\title{
CONHECIMENTO ETNOBIOLÓGICO DE UMA COMUNIDADE RURAL COMO FONTE DE INFORMAÇÃO PARA MATERIAL INFORMATIVO-EDUCATIVO
}

\author{
ETHNOBIOLOGICAL KNOWLEDGE OF A RURAL COMMUNITY AS A SOURCE OF \\ INFORMATION FOR INFORMATIVE-EDUCATIONAL MATERIAL
}

\author{
Marcos Paulo MOREIRA ${ }^{1}$; David Fernandes de SOUZA ${ }^{2}$; Elisangela Andrade ANGELO ${ }^{2 *}$
}

${ }^{1}$ Discente da Licenciatura em Ciências Biológicas, Instituto Federal do Paraná, campus Umuarama.; E-mail: marcospaulo.mcp@gmail.com; ${ }^{2}$ Docentes de Biologia do Instituto Federal do Paraná, campus Umuarama, Paraná, Brasil.; E-mail: david.souza@ifpr.edu.br;

*Autora para correspondência: elisangela.angelo@ifpr.edu.br

\begin{abstract}
RESUMO
A Etnobiologia é uma área interdisciplinar que busca analisar e estudar a forma como determinadas culturas interagem com o meio biológico, tendo como princípio a valorização dos conhecimentos culturais. Os estudos etnobiológicos e das percepções ambientais podem ser úteis para a elaboração de projetos de educação ambiental mais contextualizados. Dessa maneira, o presente trabalho teve por objetivo realizar um levantamento dos conhecimentos etnobiológicos de moradores da Vila Rural Dezenove de Dezembro, município de Alto Piquiri, noroeste do Paraná, Brasil. Além disso, o trabalho teve por objetivo criar um material informativo educativo que considera os saberes locais. Inicialmente, fez-se uma revisão bibliográfica sobre a localidade, seguida de entrevistas narrativas utilizando-se as metodologias de bola de neve e o conceito de saturação. O material das entrevistas foi estudado com base na Análise Textual Discursiva. Como resultado, os moradores entrevistados listaram diversos animais silvestres, sendo que muitos demonstram uma interação afetiva com determinadas espécies, principalmente com os passarinhos. No entanto, foi possível perceber certa repulsa e alguns conflitos em relação às serpentes. Ficou evidente que os entrevistados tinham consciência dos impactos da ação antrópica sobre a localidade onde vivem. Porém, essa percepção, muitas vezes, é tida afastada da esfera pessoal, com uma postura mais reativa que propositiva. Notou-se, ainda, que há vários elementos culturais, tais como crendices e causos a respeito da fauna. Com base nas entrevistas e no levantamento bibliográfico realizado, foi elaborada uma cartilha educativo-informativa. Esse material buscou fortalecer o sentimento de pertencimento, valorizar o conhecimento local, mas também esclarecer alguns pontos que possam levar a conflitos com a fauna. Dessa maneira, procurou-se construir um material de educação ambiental a partir do contexto local, valorizando seus aspectos culturais.
\end{abstract}

Palavras-chave: conhecimento popular, contextualização, educação ambiental, etnozoologia, percepção ambiental.

\begin{abstract}
Ethnobiology is an interdisciplinary area that analyzes and studies the culture on biological and environment issues. Ethnobiology seeks to value cultural knowledge. Ethnobiological studies and environmental perceptions can be useful for the elaboration of more contextualized environmental education projects. In this way, the present study aimed to carry out a survey of the ethnobiological knowledge of residents of Vila Rural Dezenove de Dezembro, municipality of Alto Piquiri, northwest of Paraná, Brazil. In addition, the work aimed to create educational information material that considers local knowledge. Initially, a bibliographic review on the location was made, then narrative interviews were conducted, using snowball methodologies and the concept of saturation. The interview material was studied based on the Discursive Textual Analysis. It is possible to raise a wide list of wild animals with the inhabitants, and many of them demonstrate an affectionate interaction with certain species, mainly with the birds. However, it was possible to perceive some disgust and some conflicts in relation to the snakes. It was evident that the interviewees were aware of the impacts of anthropic action on the locality where they live. However, this perception is often taken away from the personal sphere, with a more reactive than propositional posture. It was also noted that there are several cultural elements, such as beliefs and stories about the fauna. Based on the interviews and the bibliographic survey carried out, an educationalinformation booklet was prepared. This material sought to strengthen the feeling of belonging, to value local knowledge, but also to clarify some points that may lead to conflicts with fauna. In this way, we tried to build an environmental education material from the local context, valuing its cultural aspects.
\end{abstract}

Keywords: popular knowledge, contextualization, environmental education, ethnozoology, environmental perception. 


\section{INTRODUÇÃO}

$\mathrm{O}$ crescente debate sobre as questões ambientais, em especial nas últimas décadas do século XX, fez a academia aumentar seu interesse pelos saberes locais (WARREN, 1995 apud ALVES et al., 2010). Esses saberes podem ser compreendidos como as manifestações culturais de determinada comunidade, ou seja, expressam seus modos de vida e suas formas de compreender o mundo (TRÉZ, 2011). Tais saberes podem contribuir para a construção de um novo paradigma na relação do ser humano com o meio ambiente.

Em particular, para a Educação Ambiental, considerar os aspectos culturais é fundamental, pois, caso contrário, perde-se a lógica sistêmica e de inter-relações que há entre as pessoas e seu ambiente, o que prejudica a compreensão da complexidade da temática (CUNHA e LEITE, 2009). Dessa maneira, torna-se importante conhecer e caracterizar as percepções ambientais de um grupo sobre o meio ambiente, a fim de contribuir para a elaboração de políticas e propostas educativas (OLIVEIRA e CORONA, 2008).

A percepção ambiental pode ser compreendida como a maneira que o meio ambiente é percebido pelo ser humano, como ocorrem suas interações com o meio e o quanto ele conhece do ambiente ao seu redor (CUNHA e LEITE, 2009). De maneira especial, em comunidades rurais, a convivência e a interação direta com o ambiente podem promover na comunidade um conhecimento mais amplo e íntimo sobre a fauna e flora local, influenciando diretamente nos aspectos culturais dos integrantes da comunidade. O ser humano age sobre o ambiente, porém seu comportamento também é influenciado pelo meio ambiente em que está inserido, portanto, há um complexo fenômeno de interação dialética (ZACARIAS e HIGUCHI, 2017).

A compreensão da interação dialética ser humano/meio ambiente pode ser feita estudando-se a linguagem, pois por meio dela, as comunidades organizam suas percepções (SANTOS-FITA e COSTA NETO, 2007). Essa compreensão pode agregar à preservação do meio ambiente, uma vez que pode possibilitar uma visão mais completa e holística do meio ambiente local (BRANDÃO, 2002).

Segundo Silva (2016), ao se estudar as percepções e modo de vida de determinado grupo, voltados para o local em que estão inseridos, permite-se a formulação de estratégias educacionais, tanto formais quanto informais. Assim, essas estratégias propiciam uma interação e análise mais reflexiva por parte dos integrantes do grupo com o meio em que eles vivem.

A fim de estudar o conhecimento cultural referente aos temas da biologia, desenvolve-se a Etnobiologia, a qual é uma área interdisciplinar que estuda as construções culturais a respeito de temas da biologia. Essa área busca compreender a forma como as pessoas, de maneira coletiva ou individual, interagem com o ambiente (ALBUQUERQUE, 2018a, 2018b).

De acordo com Prado e Murrieta (2015), os estudos etnobiológicos precursores se sustentavam apenas na coleta de dados da biota local com os indivíduos da comunidade. Com o passar dos anos, estes estudos foram se ampliando e, além das coletas de dados superficiais, foram surgindo interesses em buscar o conhecimento tradicional que a comunidade local carregava consigo, permitindo uma compreensão mais ampla acerca da comunidade estudada e valorizando o conhecimento cultural.

A importância de se ocorrer uma aproximação entre a Etnobiologia e a educação é destaca, por exemplo, por Chagas (2013) Rosa e Orey (2014) e Trez (2011). Essa aproximação pode permitir o diálogo entre saberes, o que colabora para o enriquecimento do conhecimento de todos envolvidos no processo educativo (ALVES et al. 2010). Além disso, a Etnobiologia contribui para contextualização dos conhecimentos científicos, a partir das culturas e vivências do educando (COSTA, 2008).

É interessante notar que o conhecimento etnobiológico de uma comunidade tem valor intrínseco e, portanto, não necessita de uma validação científica para ter importância (ALVES et al. 2010). Considerando-se esse princípio, a aproximação entre Etnobiologia e educação pode contribuir para a construção de uma cultura de valorização das diferenças e, portanto, para a construção de uma sociedade mais inclusiva.

O presente trabalho foi desenvolvido na Vila Rural Dezenove de Dezembro, no município de Alto Piquiri, Noroeste do Paraná, Brasil. O local onde a comunidade vive apresenta muita pastagem devido à criação de gado para o sustento das famílias. Porém, há também porções significativas de mata nativa, bem como áreas reflorestadas e rios nas proximidades. A equipe do trabalho conta com um morador dessa comunidade, que ao longo do tempo observou que, por ser uma região rural, é frequente o aparecimento de animas silvestres nas residências. A partir dessa observação inicial, o trabalho procurou responder as seguintes questões: quais as percepções dos moradores locais quanto à interação com esses animais silvestres? Há algum conflito nessas interações? Quais conhecimentos 
etnobiológicos a comunidade apresenta? É possível desenvolver uma estratégia educativo-informativa que leve em conta as percepções e conhecimentos etnobiológicos dessa comunidade?

Dessa maneira, com o objetivo de responder às questões levantadas, desenvolveu-se um estudo etnobiológico, com base em entrevistas e revisão bibliográfica. Em seguida, elaborou-se uma cartilha informativo-educativa, com base no estudo realizado.

\section{MATERIAIS E MÉTODOS}

\section{Local da pesquisa}

O presente estudo foi realizado na Vila Rural Dezenove de Dezembro, uma comunidade rural situada a aproximadamente $2 \mathrm{~km}$ do centro do município do Alto Piquiri, noroeste do Estado do Paraná, Brasil (Figura 1). A comunidade foi inaugurada em 2000, garantindo a moradia para 35 famílias de trabalhadores rurais volantes. Atualmente, cerca de 140 pessoas residem no local

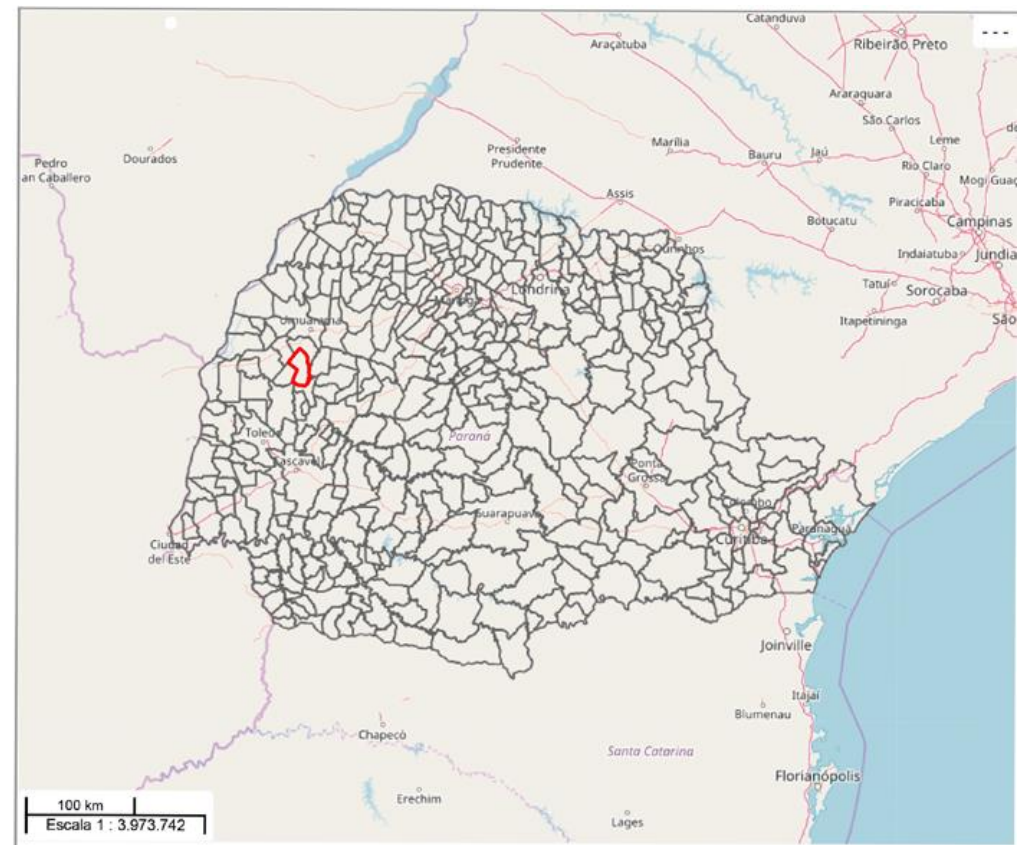

Figura 1. Localização do município de Alto Piquiri, noroeste do Paraná (Fonte: PARANÁ, 2020).

De acordo com o Instituto Brasileiro de Geografia e Estatística (2019), Alto Piquiri possui uma população estimada de cerca de 9.836 pessoas, sendo a maioria de religião católica. A população rural de Alto Piquiri corresponde a quase $18 \%$ da população total do município (IPARDES, 2019). A região se encontra no domínio de Mata Atlântica, tendo como principal caracterização a predominância de Floresta Estacional Semidecidual (PARANÁ, 2012).

\section{Levantamento bibliográfico}

Para caracterizar a comunidade, foi realizada uma revisão bibliográfica e análise documental por meio de levantamento de trabalhos sobre a região. Essa foi uma etapa importante do trabalho, com objetivo de levantar uma gama de informações relevantes, já disponíveis (FACHIN, 2006). É importante destacar que a pesquisa foi feita prioritariamente em artigos científicos. No entanto, por se tratar de uma região com poucos artigos especificamente a seu respeito, optou-se por também considerar trabalhos técnicos, bem como documentos de referência de instituições, como o Instituto Brasileiro de Geografia e Estatística (IBGE), Instituto Ambiental do Paraná (IAP) e Instituto Paranaense de Desenvolvimento Econômico e Social (IPARDES). Para o levantamento bibliográfico da fauna, utilizaram-se como referência os Estudos de Impacto Ambiental sobre hidrelétricas no rio Piquiri (PARANÁ, 2012), corpo de água que se localiza bem próximo à comunidade.

\section{Pesquisa de campo e Análise Textual Discursiva}

A fim de permitir uma melhor compreensão sobre o conhecimento etnobiológico, foram realizadas entrevistas com moradores da comunidade rural. Destaca-se que para a compreensão da percepção ambiental e etnobiológica da comunidade, é essencial incluir uma abordagem qualitativa, tendo em 
vista a complexidade cultural, que dificilmente se compreende apenas com abordagens quantitativas. Além disso, as entrevistas permitem maior interação entre os pesquisadores e os entrevistados, bem como uma melhor compreensão da temática sob a ótica do morador (CUNHA e LEITE, 2009; BRITTO JÚNIOR e FERES JÚNIOR, 2012).

As entrevistas realizaram-se mediante um roteiro de perguntas especialmente preparado para esse trabalho, segundo seu objetivo, a saber: 1) Quais animais silvestres você costuma ver com frequência próximos à sua residência? 2) Qual a sua atitude quando vê esses animais? 3) Em sua opinião, por que esses animais silvestres estão se aproximando das residências? 4) Há outros animais silvestres que você vê com menor frequência? Quais são eles? 5) Você já teve alguma situação de conflito com algum desses animais silvestres? 6) Você considera a presença desses animais boa ou ruim? 7) Você conhece alguma lenda ou conto que fale sobre algum animal silvestre? Poderia contá-la?

Destaca-se que, apesar de existir um roteiro, as entrevistas foram conduzidas com liberdade para que ocorressem inserções de novas perguntas, de acordo com a narrativa estabelecida durante o processo, sendo, por isso, chamada de entrevista narrativa. Para Muylaert et al. (2014, p. 2), "há nas entrevistas narrativas uma importante característica colaborativa, uma vez que a história emerge a partir da interação, da troca, do diálogo entre entrevistador e participantes."

As entrevistas foram realizadas após a devida autorização e consentimento do entrevistado, mediante assinatura dos termos de consentimento, posteriormente à explicação da proposta do projeto. O projeto foi aprovado pelo Comitê de Ética do Instituto Federal do Paraná, sob o parecer de número 3.442.011/2019.

A escolha dos moradores para serem entrevistados seguiu a metodologia denominada como bola de neve, em que o entrevistado indica quem será o próximo possível participante da entrevista. Segundo Vinuto (2016), a metodologia bola de neve é uma forma de abordar grupos, nos quais os primeiros entrevistados indicam novas pessoas para serem entrevistadas, podendo, assim, seguir uma linha de pensamento e obtenção de dados mais completos, visto que para se indicar o novo entrevistado, o indicador acredita que tal pessoa possa agregar ao assunto. Além disso, tal metodologia favoreceu no sentido de que as pessoas da comunidade, reconhecidas por eles mesmos como referência no assunto em questão, fossem apontadas e mapeadas. No presente trabalho, o morador mais antigo da comunidade foi o primeiro a ser entrevistado.

A quantidade de entrevistados foi estabelecida pelo critério de saturação. De acordo com esse critério, a saturação ocorre quando novas entrevistas não fornecem elementos que permitam aprofundar o conhecimento sobre o tema (FONTANELLA et al., 2011). Portanto, a quantidade de pessoas a serem entrevistadas foi conduzida até quando novas entrevistas não trouxeram informações relevantes para a pesquisa.

Para garantir que informações não fossem perdidas durante as entrevistas, foi solicitada a permissão do entrevistado para realizar a gravação em áudio, garantido a ele o direito de aceitar ou não. Além disso, assegurou-se que nenhuma informação foi ou será utilizada para outros fins que não sejam os constantes no projeto. As entrevistas gravadas foram transcritas a fim de compor o corpus para análise das informações.

As entrevistas foram analisadas de forma a se caracterizar a percepção ambiental e o conhecimento etnobiológico da comunidade, utilizando-se a metodologia denominada Análise Textual Discursiva (ATD). Essa metodologia consiste em dividir o corpus textual das entrevistas em unidades de sentido, seguidos por um processo de categorização e construção de um metatexto, o qual permite uma análise do tema em questão (MORAES e GALIAZZI, 2016). De acordo com Moraes (2003), para que a análise seja feita, o corpus textual é fragmentado em um processo de decomposição. A partir desse processo, é possível reconhecer novas percepções sobre o tema em estudo.

Com base no conhecimento etnobiológico da comunidade e a caracterização bibliográfica do local, foi confeccionada uma cartilha informativo-educativa.

\section{RESULTADOS E DISCUSSÕES}

\section{Conhecimento etnobiológico da comunidade rural}

Ao todo, foram entrevistados nove moradores, o que corresponde a 6,4\% dos moradores locais. Houve uma porcentagem levemente maior de mulheres $(55,5 \%)$. Todos os entrevistados eram adultos (acima de 18 anos), sendo 44,4\% acima de 60 anos, 22,2\% entre 40 e 60 anos e 33,3\% entre 20 e 40 anos. Em relação à sua ocupação, a maioria $(77 \%)$ pratica a agricultura e a pecuária de subsistência, porém exercem outras atividades econômicas adicionais. 
De acordo com Rosa e Orey (2014), um pesquisador ou educador que trabalhe sobre a perspectiva etnobiológica deve estar aberto à nova cultura, livre de julgamentos de valores, a fim de que possa compreender os saberes que está conhecendo. No presente estudo, um dos pesquisadores é parte integrante da comunidade, o que facilita essa compreensão. Além disso, a realização da pesquisa foi uma oportunidade de estabelecer um diálogo entre os conhecimentos culturais de sua comunidade com os conhecimentos científicos presentes na academia. Dessa maneira, o estudo parte do princípio de que cada conhecimento tem seu valor intrínseco e, portanto, busca-se o compartilhamento de saberes e não a validação do conhecimento local pelo científico (ALVES et al., 2010; CHAGAS, 2013).

Utilizando-se a ATD para análise das entrevistas, definiu-se como categorias de análise: "Identificação de animais silvestres", "Presença de animais silvestres" e "Tradições culturais sobre a fauna silvestre". Na categoria de análise "Identificação de animais silvestres", procurou-se identificar quais eram os animais mais lembrados pelos moradores (Figura 2). O grupo das aves ranqueou como mais citado, seguida pelo grupo dos mamíferos. Possivelmente, fatores como a aproximação das residências e o som característico do canto das aves fizeram com que estes animais tivessem sua presença revelada e fossem mais facilmente reconhecidos e identificados pelos moradores. Anfíbios e répteis ocuparam a terceira colocação nas citações. Observou-se que os anfíbios foram citados de forma genérica, sem inclinação a uma possível diferenciação, ou seja, as espécies foram nomeadas genericamente como sapo e rã.

No grupo dos répteis, as serpentes foram citadas de forma genérica (cobra), mas também por alguns nomes comuns de identificação, como cascavel, coral, coral-falsa, cobra-verde, dormideira, entre outros. Já os lagartos somente foram citados por este nome genérico. Os insetos obtiveram a menor quantidade de citações e nenhuma referência foi feita a outros artrópodes. É possível que, mesmo os artrópodes sendo os animais mais numerosos da fauna, o seu tamanho reduzido e o pouco conhecimento da sua morfologia levaram a população local a não os identificar como animais silvestres.

Em geral, as aves e os mamíferos têm forte apelo sentimental. Os trabalhos de Marques (1998, 2010) demonstram como as aves ocupam um lugar de destaque no imaginário humano, estando presente em vários contos populares, ritos e crendices. Oliveira e Corona (2008) também citam que as percepções ambientais sofrem forte influência estética; provavelmente, por serem considerados mais bonitos do que répteis e anfíbios, as aves e os mamíferos apresentaram maiores citações.

As Tabelas 1 a 3 apresentam as principais espécies citadas pelos moradores, de acordo com os nomes populares por eles atribuídos. A fim de dialogar com o saber científico, são também apresentados os nomes científicos de algumas aves, mamíferos e répteis comuns na região, conforme levantamento bibliográfico. Destaca-se que, referente ao levantamento bibliográfico, há várias outras espécies, porém, optou-se por listar aquelas que possuíam uma correspondência com a citação dos moradores. Nos casos em que os moradores citaram nomes genéricos, por exemplo lagarto, optou-se por colocar o nome científico da espécie mais comum, de acordo com os estudos sobre a região.

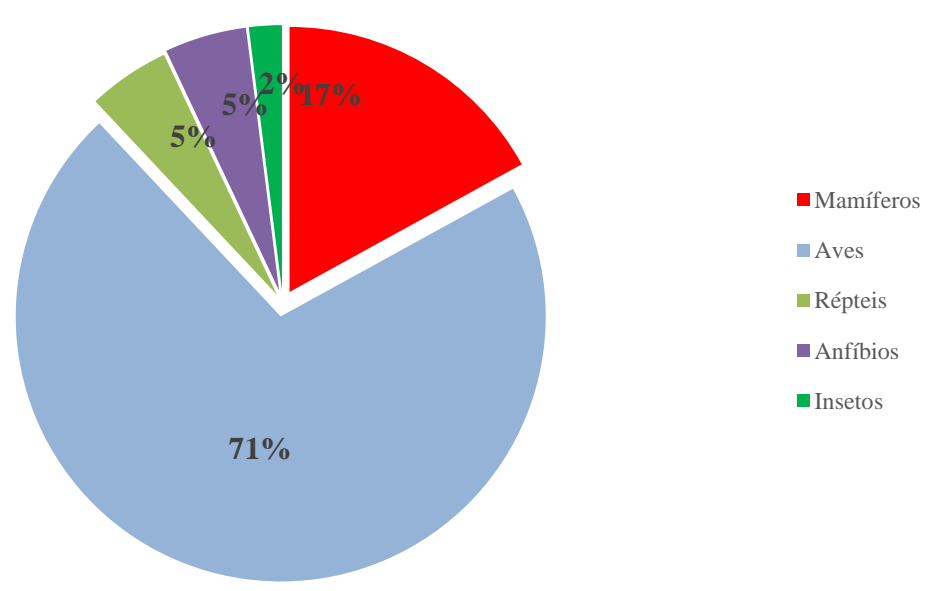

Figura 2: Grupos de animais citados pela comunidade (Fonte: autores). 
Tabela 1. Répteis citados pela comunidade e nomes científicos resultantes de levantamento bibliográfico.

\begin{tabular}{ll}
\hline Citados pela comunidade & Levantamento bibliográfico \\
\hline Cascavel & Caudisona durissa (cascavel) \\
Cobra-verde & Philodryas olfersii (cobra-verde) \\
Coral & Micrurus altirostris (cobra-coral verdadeira) \\
Dormideira & Dipsas alternans (cobra dormideira) \\
Falsa-coral & Erythrolamprus aesculapii (falsa-coral) \\
Lagarto & Tupinambis merianae (teiú) \\
\hline
\end{tabular}

Tabela 2. Mamíferos citados pela comunidade e nomes científicos resultantes de levantamento bibliográfico.

\begin{tabular}{ll}
\hline Citados pela comunidade & Levantamento bibliográfico \\
\hline Furão & Galictis cuja (furão) \\
Gambá & Didelphis albiventris (gambá) \\
Lontra & Lontra longicaudis (lontra) \\
Macaco & Cebus nigritus (macaco-prego) \\
Morcego & Desmodus rotundus (morcego-vampiro) \\
Porco-espinho/ Luiz-cacheiro/ Ouriço & Sphiggurus spinosus (ouriço) \\
Tatu/ Tatu-galinha & Dasypus novemcinctus (tatu-galinha) \\
\hline
\end{tabular}

Tabela 3. Aves citadas pela comunidade e nomes científicos resultantes de levantamento bibliográfico.

\begin{tabular}{|c|c|}
\hline Citados pela comunidade & Levantamento bibliográfico \\
\hline Anu-branco & Guira guira (anu-branco) \\
\hline Anu-preto & Crotophaga ani (anu-preto) \\
\hline Asa-branca/ Pomba-do-ar/ Pomba-grande & Patagioenas picazuro (asa-branca) \\
\hline Beija-flor & Hylocharis chrysura (beija-flor-dourado) \\
\hline Bem-te-vi/ Caga-sebo & Pitangus sulphuratus (bem-te-vi) \\
\hline Canário & Basileuterus flaveolus (canário-do-mato) \\
\hline Cardeal/ Galo-campino & Lanio cucullatus (tico-tico-rei) \\
\hline Coleirinha & Sporophila caerulescens (coleirinho, papa-capim) \\
\hline Coruja & Athene cunicularia (buraqueira) \\
\hline Curicaca & Theristicus caudatus (curicaca) \\
\hline Curruila & Troglodytes musculus (corruíra, cambaxirra) \\
\hline Garça & Bubulcus ibis (garça-vaqueira) \\
\hline Gavião & Rupornis magnirostris (gavião-carijó) \\
\hline Gralha & Cyanocorax chrysops (gralha-picassa) \\
\hline Guacho & Cacicus haemorrhous (guaxe) \\
\hline Guarani (curió-guarani) & Sporophila angolensis (curió) \\
\hline Juriti & Leptotila verreauxi (juriti) \\
\hline Loro/ papagaio & Amazona aestiva (papagaio) \\
\hline Maritaca & Aratinga leucophthalma (periquitão-maracanã) \\
\hline Merro & Gnorimopsar chopi (melro, pássaro-preto) \\
\hline Periquito & Brotogeris chiriri (periquito-de-encontro amarelo) \\
\hline Pinica-pau & Dryocopus lineatus (pica-pau-de-banda-branca) \\
\hline Pomba & Zenaida auriculata (avoante) \\
\hline Pombinha marronzinha & Columbina talpacoti (rolinha) \\
\hline Quero-quero & Vanellus chilensis (quero-quero) \\
\hline Sabiá & Turdus leucomelas (sabiá-barranco) \\
\hline Sanhaçu & Tangara sayaca (sanhaçu-cinzento) \\
\hline Tico-tico & Zonotrichia capensis (tico-tico) \\
\hline Tucano & Pteroglossus castanotis (araçari-castanho) \\
\hline Vivi & Euphonia chlorotica (fim-fim) \\
\hline
\end{tabular}

Na categoria de análise "Presença de animais silvestres", procurou-se investigar qual a opinião dos moradores sobre a convivência com essa fauna, bem como se eles identificam os motivos da aproximação desses animais com as moradias humanas. Com a análise das entrevistas, pode-se perceber que os entrevistados apresentam admiração e zelo por aves, como pode ser percebido nas falas a seguir:

"Olha que beleza os passarinzinhos estão aumentando. Eu acho muito bonito os bichinho no terreiro" (morador 3). 
"A gente aprecia né! Vê uma coisa nova, a gente vai gostar, procura ficar mais focado naquele tipo de passarinho, coisa que você não tem costume de ver, não tem costume, então você fica mais querendo observar mais" (morador 8).

Assim como nos estudos de Marques (1998, 2010) e Oliveira e Corona (2008), citados anteriormente, nota-se mais uma vez o forte apelo afetivo e estético das aves para a comunidade. Porém, quando se trata de répteis, alguns moradores citaram uma percepção negativa sobre eles: "Eu mato a cobra! Eu chamo um passarinho para dar uma bicada na boca dela" (morador 2).

Devido às concepções e aos mitos, em muitas culturas o medo e a repulsa em relação às serpentes são notórios (FERNANDES-FERREIRA et al., 2011). Essas percepções podem refletir na ação ao encontrar esses animais, que podem acabar sendo eliminados (ARAUJO e LUNA, 2017; LIMA et al., 2018). Tal receio afeta animais inofensivos, que acabam sendo confundidos com animais perigosos à saúde, como muitas serpentes não peçonhentas que são eliminadas pela falta de conhecimento. As falas e até mesmo a linguagem corporal de vários entrevistados deixam claro a aversão às serpentes e até mesmo seu extermínio, independente de qual seja a espécie. As falas a seguir demonstram essa aversão: "Não gosto muito dependendo do animal [...]. Se for cobra, essas coisas! (morador 4)"; "Cobra, só uma vez que o pai matou uma cobra. Graças a Deus (morador 5)".

Percebe-se, portanto, que os fatores culturais, aliados à falta de informações, podem contribuir negativamente para a preservação das serpentes. Por isso, ações de educação ambiental, com ênfase na sensibilização, precisam considerar os conflitos com esses répteis. Nessas ações é interessante apresentar a importância ecológica destes animais, conhecer e trabalhar as informações que a comunidade possa ter a fim de proporcionar uma interação menos agressiva com as serpentes (MOURA et al., 2010; JERONIMO, 2013).

Em relação à proximidade dos animais silvestres com as residências, com exceção dos répteis e alguns felinos, a presença é considerada positiva. Segundo os moradores entrevistados, essa proximidade com os animais acaba sendo um fator educativo, pois permite que se conheça mais sobre a fauna, principalmente para as crianças, como pode ser visto na seguinte fala:

"Ah, eu acho bacana, que é legal, viu? Nossa! Principalmente para as crianças para conhecer, ver. Tem criança da cidade que eu até brinco com os filhos do meu chefe [...] né? Eles da cidade total, trancado no apartamento, não vê nada. E aqui as crianças já vê, já sabe que é macaco, já sabe quem é, né? Sabe que [...] sabe que as coisas né? Eles vieram aqui no aniversário, o moleque olhou para a vaca e falou: 'O que que é isso?'. Então não sabe, né? [...]. É um ponto positivo sim, que eles aprendem vão sabendo, saber o que é né? E colocar nome eu acho bacana sim" (morador 2).

De acordo com os estudos de Tuan, citados no trabalho de Oliveira e Corona (2008), os indivíduos nativos de um local apresentam uma percepção mais complexa do seu meio, diferente de um visitante, o qual geralmente tem a percepção mais voltada apenas para questões estéticas genéricas do ambiente. Tal constatação pode ser percebida na fala acima do morador, a respeito das crianças da cidade.

Ao serem indagados sobre o porquê da aproximação dos animais silvestres das moradias humanas, houve grande ênfase à busca por alimentos pelos animais. De acordo com os moradores, a aproximação se deve ao fato de que muitas residências apresentam árvores frutíferas e plantas dotadas da produção de sementes, o que acaba atraindo estes animais. Além disso, é também apontado que determinados animais, como lagartos, gralhas, gambás e gaviões, vêm em busca de ovos e filhotes de aves domésticas, causando significativo prejuízo econômico para a comunidade. No entanto, com relação aos pássaros com forte apelo estético, grande parte dos moradores acaba fornecendo alimentos, como pode ser percebido na seguinte fala:

"Ah, eu procuro jogar uma coisa assim para ver se amansa mais eles para não ir embora. Eu acho bonito demais, eu tenho dó de ver eles indo embora e a minha atitude é consegui cuidar para eles permanecer no lugar" (morador 3). 
Além da busca por alimento, outro fator que leva à aparição dos animais silvestres, de acordo com os moradores, é a falta de habitat devido ao desmatamento e queimadas, como foi apontado nas entrevistas:

"O ser humano tá acabando com todas as reservas, todas as matas, onde era para ficar esses animais! Não tá tendo mais espaço, daí acaba vindo para cá [...]. Então eles estão sendo expulsos do local deles de origem, né? Então acho que a culpa é nossa mesmo, né? É, porque antigamente não era assim!" (morador 6).

"Eu acho que tá faltando espaço para eles, né, então por isso que estão aparecendo aqui, né? Falta esse espaço, ele [...]. Eu acho que alguém está invadindo o espaço dele, né? As matas estão caindo, né? Então, o que que eu fico pensando [...] é o habitat deles, né? Que estão fazendo, estão acabando com a selva" (morador 4).

As falas acima sobre a percepção ambiental de alguns moradores podem ser comprovadas pelos estudos realizados na região, pois, embora apresente bolsões de mata fechada, a localidade tem muitas áreas antropizadas. Segundo o Estudo de Impacto Ambiental da Usina Hidrelétrica Apertados (PARANÁ, 2012), aproximadamente $88 \%$ da região apresentam ações antrópicas, como agricultura, pastagens, áreas urbanas, entre outras, e apenas cerca de $11 \%$ da região se destinam às áreas de vegetação, como Floresta Estacional Semidecídua, Floresta Ombrófila Mista, reflorestamento e vegetação de transição entre Florestas Estacional Semidecídua e Ombrófila Mista.

É interessante notar que mesmo reconhecendo a destruição do habitat, não há uma percepção pessoal sobre a questão por parte do morador 4. Observa-se em sua fala expressões como "alguém está invadindo" e "as matas estão caindo", ou seja, procura-se afastar da questão, mesmo que de forma inconsciente. Essas falas demonstram um tipo de consciência ambiental denominada "consciência sem comprometimento", que afasta o problema de sua esfera pessoal e tende a comportar-se muito mais de forma reativa do que propositiva (OLIVEIRA e CORONA, 2008). Trabalhar uma educação mais contextualizada e com exemplos locais pode ser uma estratégia para construção de uma consciência ambiental mais propositiva.

Além do alimento e da falta de habitat, alguns moradores apontam a possível soltura de animais pelo Ibama próximo à comunidade: "Com certeza, eu não sei se é o Ibama que soltou para nós aqui, no matinho, né? Eu acho que deve ser o Ibama que soltou aqui" (morador 3). Entretanto, tal informação fica sem fundamentos, visto que são apenas especulações. Muito se é discutido pelos moradores que o Ibama, a Força Verde e outros órgãos ambientais acabam por soltar animais silvestres, em especial felinos, em locais nas redondezas das moradias e que isso pode acabar trazendo perigo aos moradores. Porém, segundo o Ibama (2016), os animais silvestres são soltos apenas em propriedades rurais devidamente autorizadas e cadastradas.

Em relação à categoria "Tradições culturais sobre a fauna silvestre", notou-se que muitos moradores tiveram dificuldades em falar sobre esse aspecto, permitindo observar que esse tema não é muito discutido entre eles. Com isso, essas informações acabam passando despercebidas pela comunidade. Entretanto, ao citar exemplos sobre tradições e crendices, alguns acabam tendo recordações de alguns eventuais costumes, como citado por eles a respeito dos répteis:

"Se ele tiver choco (lagarto), você for pro lado dele ele te bate. Dai você não apanha de uma pessoa, você apanha do lagarto! Ele bate mesmo" (morador 3).

"O lagarto, a única lenda que eu sei deles é de uma família [...]. Isso já faz muitos anos, [...] eu era criança, quando aconteceu isso na família de homem que contava para gente que tinha acontecido na família dele, que matou o lagarto para comer e disse que o lagarto tinha brigado com cobra e fizeram o lagarto para comer, e da família só escapou uma velhinha que era doente, tomava remédio e não podia comer! Então ela não comeu, os que comeu morreu tudo! Que disse que lagarto briga cobra né? Não sei, eu nunca vi, mas não vou duvidar" (morador 3 ). 
Referente às aves, dentre as lendas e atitudes citadas pelos moradores, destacam-se histórias sobre corujas e urutaus:

"Falam que quando a coruja passa, tá agorando as pessoas, né, na casa! Fala que vai morrer o parente ou uma pessoa da casa [...]. E esse negócio de galo ficá cantando na porta também, que fala essas coisa ruim, né? Chamando morte na familia, acidente, essas coisas aí" (morador 2).

"Eu lembro que tem um pássaro chamado urutau. Minha avó falava que quando aquele pássaro beirava a casa não era um bom sinal [...]. E não gostava quando aquele pássaro ficava em casa" (morador 1).

E sobre os mamíferos, os moradores entrevistados citaram informações sobre o porco-espinho e macacos:

"Principalmente desse, o porco que é o Ouriço! Muita gente dizia, se passar perto, mexer, ele chacoalha e joga espinho! Negativo! Não acontece nada disso! A não ser que você for lá então, bater a mão nele, aí ele vai te espinhá! E o cachorro, principalmente [...] então ele pega, mas não que ele jogou! Agora, daquele espinho dele, circular, entra para dentro, circula no corpo da pessoa ou de uma criação, isso aí sim! Isso aí acontece! A descendência é só ir para frente! Se conseguir arrancar ou então, cortou ele ali também, aquela ponta morre e ela não tem vida para seguir" (morador 7).

"Para ver o que que é os bichinho, né? Na época eu era moleque, vixe faz muitos anos e eu morava numa fazenda, só por dentro da Mata. Eu andava mais de quilometros para sair na cabeceira onde era a roça nossa. Aí eu levava uma espingarda, aquele tempo, né? Apareceu um bando deles (macacos). Aí eu vi uma com filhotinho. Eu pensei derrubar ela para tirar o filhotinho, que antigamente nego fazer isso, né? Criar ele em casa. Aí cara, pa [...] eu aprontei espingarda, ela levou, levou os bracinhos aqui, tirou o fiim e botou na frente dela. Então assim, agora se analisa bem o que é a mãe. Ela falou, você vai me matar? E o meu filho? Você vai falar agora, do jeito que tá aqui, você vai matar ele e vai matar eu também! né? Então, quer dizer que no sentido do bichinho ela já deu a demonstração que ela tava amamentando, que ela tava com filhotinho para criar [...] também, abaixei, falei da minha parte, nunca mais aponto arma para um bichinho desse!" (morador 7).

Ao ser comparado com dados apresentados por Fernandes-Ferreira et al. (2011), Souza et al. (2013) e Santos et al. (2015), pode-se perceber que mitos e crendices são abordados em inúmeras comunidades e muitos acabam sendo difundidos pelo fato de as pessoas acreditarem ser fatos verídicos, ou mesmo por formarem elementos já arraigados culturalmente. Isso pode refletir em pontos negativos para determinados animais, como no caso das crendices sobre a coruja, o lagarto e o urutau.

A presença de crenças sobre animais como presságios é comum em várias comunidades (MARQUES, 1998, 2010). É comum, também, a valoração da fauna, de acordo com essas crenças, ou seja, os animais podem ser considerados bons ou ruins a depender de sua relação com o humano, em uma visão marcadamente antropocêntrica. O estudo etnobiológico de Cadima e Marçal Júnior (2004) apresenta uma categorização de aves que são tidas como benéficas por uma comunidade do Sudeste brasileiro, enquanto outras aves são consideradas maléficas, de acordo com suas crenças em relação ao ser humano.

Na história contada pelo morador sobre a macaquinha, fica evidente como a percepção ambiental é influenciada pelas interações ocorridas com a fauna. Conforme apontado por Zacarias e Higuchi (2017), as histórias e interações que despertam emoções nos moradores têm forte influência sobre o significado que eles atribuem às espécies. Por ser um fato ocorrido na localidade, essas histórias podem contribuir para uma maior reflexão ambiental, visto que os moradores se identificam com elas (SILVA, 2016). 


\section{Material informativo-educativo}

Em geral, os sistemas educativos e seus materiais tendem a ser urbanocêntricos, ou seja, apresentam as informações a partir de uma perspectiva de quem mora na cidade (LINS et al., 2011). O desenvolvimento de materiais educativos, que levem em conta a realidade e conhecimento das populações rurais, pode contribuir para a valorização da cultura do campo, bem como para a contextualização dos conhecimentos científicos. Dessa maneira, com base em toda a análise, foi produzido um material informativo-educativo (cartilha). Foram feitas duas versões da cartilha, uma adulta e outra infantil. Esses materiais serão entregues à escola próxima à comunidade, bem como aos moradores da Vila Rural Dezenove de Dezembro. Com isso, a cartilha será uma forma de compartilhar com a comunidade o conhecimento construído nesse estudo.

Optou-se por iniciar a cartilha fazendo um breve resgate sobre as informações gerais e a história da comunidade. Esse início foi pensado no sentido de rememorar o local aos próprios moradores a fim de fortalecer seu senso de pertencimento. De acordo com Cardoso et al. (2017):

Podemos afirmar que o sentimento de pertencimento implica em olhar e reconhecer-se. Provoca, ainda, pensar em si mesmo como integrante de uma sociedade que atribui símbolos e valores éticos e morais, o que destaca características culturais. O sentimento manifestado pelos sujeitos sociais acerca do ambiente em que vivem carrega as singularidades de sua formação e encerra circunstâncias emocionais, muitas vezes, apenas vividas ali (CARDOSO et al., 2017, p. 89).

Observa-se que, embora os moradores demonstrem apreço pelo local, muitos ainda não se veem como pertencentes a uma comunidade. Apesar de os moradores demonstrarem conhecimento e intenso relacionamento entre si, o fato de a comunidade rural ter cerca de vinte anos pode contribuir para essa não identificação enquanto grupo. Conforme apresentado no trabalho de Koszela e Ramos (2012), a memória, a identidade cultural e o pertencimento estão intimamente relacionados. Dessa maneira, a cartilha poderá contribuir para a consolidação do pertencimento dos moradores.

A cartilha segue com informações sobre a vegetação da região, apresentando as principais espécies de árvores, a importância da vegetação, bem como a situação atual do local, onde se observa forte ação antrópica. Além disso, buscou-se estabelecer uma relação entre a ação antrópica e os impactos sobre a fauna da região, a partir de exemplos locais, a fim de contextualizar os conceitos. Dessa maneira, assim como proposto por Silva (2016), buscou-se construir uma estratégia que partisse da realidade e das percepções dos próprios moradores, o que aproxima os conhecimentos que eles já apresentam de novos conceitos científicos.

As páginas seguintes da cartilha destacaram os animais citados pelos moradores. Conforme indicado pelos trabalhos de Moura et al. (2010) e Jeronimo (2013), ao apresentar a fauna foi dada especial atenção à importância ecológica, bem como foram esclarecidas algumas informações equivocadas sobre os animais. Dessa maneira, procurou-se valorizar as percepções locais, mas também esclarecer alguns pontos, como os conflitos com as serpentes e a suposta soltura de animais selvagens por órgãos ambientais. Com isso, mais uma vez, procurou-se valorizar o conhecimento que os moradores já tinham e, a partir deles, apresentar informações que visam uma convivência mais harmônica.

Por fim, a cartilha apresenta algumas reflexões, com base em imagem do local e em um dos relatos levantados durante as entrevistas (Figura 3). O caso foi escolhido a fim de valorizar as histórias locais, rememorar acontecimentos e discutir as questões ambientais a partir de uma ótica contextualizada. A história narrada pelo morador apresenta de maneira clara a interrelação entre o ser humano e seu ambiente, sendo, portanto, uma ótima oportunidade para se trabalhar a temática ambiental, considerando-se as interações locais (CUNHA e LEITE, 2009). Buscou-se, assim, realizar uma interação entre a "cultura científica" e a cultura local a fim de que novas reflexões sejam consideradas e ambos, pesquisadores e moradores, aprendam mutuamente (FREITAS, 2012).

\section{CONCLUSÕES}

A complexidade ambiental tende a ser mais bem compreendida quando se tem uma visão holística a seu respeito. Para que isso ocorra, é essencial considerar as percepções e conhecimentos etnobiológicos das comunidades humanas, presentes nos diferentes ambientes. Destaca-se que esses 
conhecimentos devem ser reconhecidos como tendo valor intrínseco, sendo o processo de estudo etnobiológico uma troca de saberes não hierarquizados. No presente estudo, pôde-se conhecer as percepções ambientais de uma comunidade rural do noroeste paranaense.

Retomando as questões iniciais que motivaram esse trabalho, pôde-se notar que as interações com os animais silvestres realmente são frequentes, sendo que os moradores entrevistados citaram vários animais que conseguem identificar linguisticamente. Destaca-se que há um grande apreço dos moradores em relação às aves, em especial aos passarinhos. No entanto, há algumas interações negativas com cobras, as quais tendem a causar medo em muitos moradores. Como fruto dessas interações negativas, as cobras são mortas, mesmo espécies que não apresentam risco aos humanos ou às suas criações.

Os moradores entrevistados demonstram ter percepção da ação antrópica sobre o ambiente, porém, não trazem essa discussão para o campo pessoal. Com isto, problemas ambientais, como desmatamentos, ainda que reconhecidos, não são pensados a partir de uma perspectiva de envolvimento.

Ainda por meio das entrevistas, foi possível notar que há várias crenças na comunidade sobre determinadas espécies, como o mau agouro causado por corujas e urutau. Levantou-se também histórias ocorridas na comunidade que podem servir para a reflexão sobre o papel do ser humano em relação ao meio ambiente.
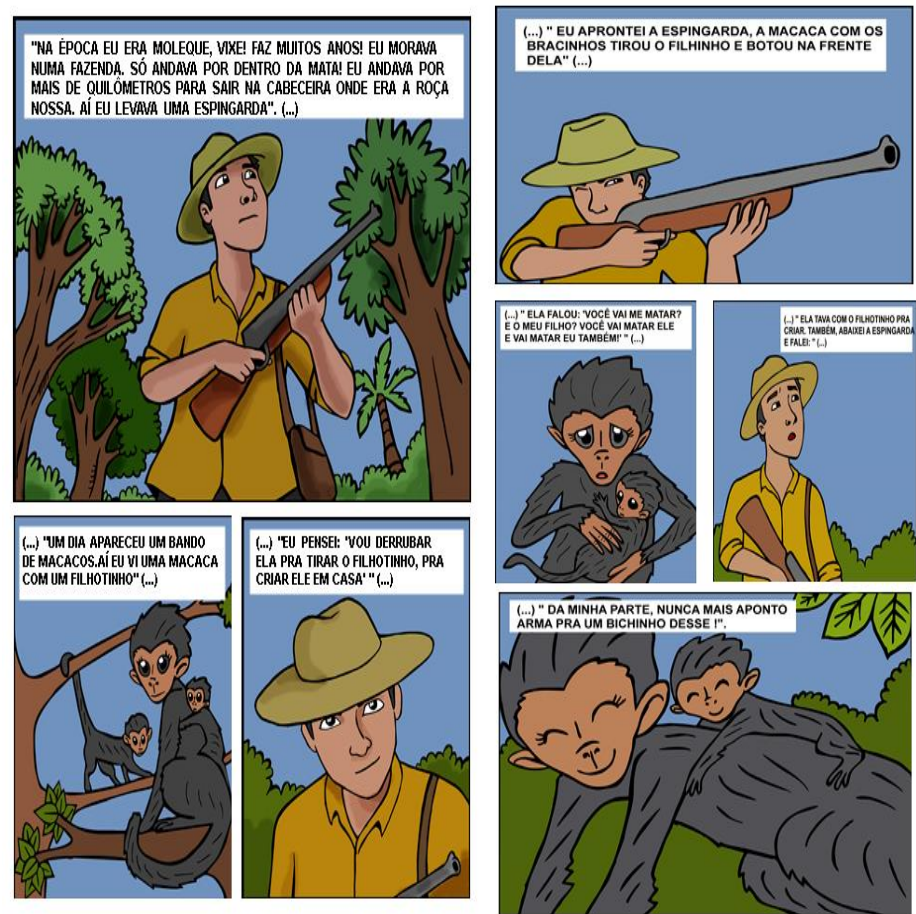

Figura 3: "Causo" apresentado na cartilha desenvolvida com base nas informações levantadas na pesquisa (Fonte: autores e ilustrações Paulo Henrique Lopes).

Foi interessante observar que muitos moradores não reconhecem a localidade como uma comunidade, sendo evidente a carência de senso de pertencimento por parte de alguns. O que indica a necessidade de resgate histórico e da memória cultural local. Sendo esse um ponto interessante para estudos futuros na comunidade.

A organização dos dados coletados e analisados permitiu construir cartilhas informativo-educativas para serem distribuídas na comunidade e escolas próximas, a fim de que mais pessoas tenham acesso às informações obtidas na comunidade. Estudos futuros podem ser desenvolvidos a fim de avaliar o impacto desse material nas escolas e mesmo na comunidade, verificando como um material construído a partir do contexto local pode contribuir para a sensibilização ambiental.

Nota-se que apesar de muitos moradores dizerem e acreditarem não possuírem informações relevantes, no momento da entrevista eles acabam transmitindo seu conhecimento, que deve ser valorizado, pois esses saberes locais possibilitam a abertura de novos caminhos em prol da educação ambiental contextualizada. 


\section{AGRADECIMENTOS}

Os autores agradecem a Paulo Henrique Lopes por, gentilmente, ter ilustrado a cartilha. Especial agradecimento também aos moradores da Vila Rural Dezenove de Dezembro que compartilharam seus conhecimentos e saberes.

\section{REFERÊNCIAS}

ALBUQUERQUE, U. P. de. Etnobiologia: bases ecológicas e evolutivas. 2. ed. Recife: NUPEEA, 2018a. 208p.

ALBUQUERQUE, U. P. de. Introdução à etnobiologia. 2. ed. Recife: NUPEEA, 2018b. 288p.

ALVES, A. G. C. et al. Conhecimento local e produção animal: uma perspectiva baseada na Etnozootecnia. Archivos de Zootecnia, Córdoba, v. 59, n. R, p. 45-56, 2010.

ARAUJO, D. F. S.; LUNA, K. P. O. Os répteis e sua representação social: uma abordagem etnozoológica.

Ethnoscientia, Botucatu, v. 2, n. 1, p. 1-15, 2017.

BRANDÃO, C. R. A educação como cultura. Campinas: Mercado de Letras, 2002. 255p.

BRITTO JÚNIOR, Á. F. de; FERES JÚNIOR, N. A utilização da técnica da entrevista em trabalhos científicos. Revista Evidência, Araxá, v. 7, n. 7, 237-250, 2012.

CADIMA, C. I.; MARÇAL JUNIOR, O. Notas sobre etnoornitologia na comunidade do distrito rural de Miraporanga, Uberlândia, MG. Bioscience Journal, Uberlândia, v. 20, n. 1, jan/abr 2004.

CARDOSO, D. et al. Espacialidades e ressonâncias do patrimônio cultural: reflexões sobre identidade e pertencimento. Got - Journal of Geography and Spatial Planning, [s.1.], v. 1, n. 11, p. 83-97, 2017.

CHAGAS, F. B. A Etnobiologia na Educação Escolar: proposta de interação entre o conhecimento científico e popular. 2013. Monografia (Especialização em História da Ciência) - Campus Erechim, Universidade Federal da Fronteira Sul, 2013.

COSTA, R. G. A. Os saberes populares da Etnociência no ensino das Ciências Naturais: uma proposta didática para aprendizagem significativa. Revista Didática Sistêmica, Porto Alegre, v. 8, p. 162-172, 2008.

CUNHA, A. S.; LEITE, E. B. Percepção ambiental: implicações para a educação ambiental. Sinapse Ambiental, p. 66-79, 2009.

FACHIN, O. Fundamentos de metodologia. 5. ed. São Paulo: Saraiva, 2006. 209p.

FERNANDES-FERREIRA, H. et al. Crenças associadas a serpentes no estado do Ceará, Nordeste do Brasil. Sitientibus série Ciências Biológicas, Feira de Santana, v. 11, n. 2, 153-163, 2011.

FONTANELLA, B. J. B. et al. Amostragem em pesquisas qualitativas: proposta de procedimentos para constatar saturação teórica. Cadernos de Saúde Pública, Rio de Janeiro, v. 27, p. 388-394, 2011.

FREITAS, F.; S. de. A diversidade cultural como prática na educação. Curitiba: InterSaberes, 2012. 140p.

IBAMA, Instituto Brasileiro do Meio Ambiente e dos Recursos Naturais Renováveis. Centros de Triagem de Animais Silvestres (Cetas). 2016. Disponível em: <https://www.ibama.gov.br/fauna-silvestre/cetas/o-quesao-os-cetas\#devolvidos> Acesso em: 30 maio 2020.

IBGE, Instituto Brasileiro de Geografia e Estatística. População estimada: IBGE, Diretoria de Pesquisas, Coordenação de População e Indicadores Sociais, Estimativas da população residente com data de referência $1^{\circ}$ de julho de 2019. Disponível em: <https://cidades.ibge.gov.br/brasil/pr/alto-piquiri/panorama>. Acesso em: 30 maio 2020.

IPARDES, Instituto Paranaense de Desenvolvimento Econômico e Social. Caderno Estatístico: Município de Alto 2019.2 Piquiri. 20 Disponível <http://www.ipardes.gov.br/cadernos/MontaCadPdf1.php?Municipio=87580\&btOk=ok>. Acesso em: 30 maio 2020.

JERONIMO, B. C. A educação ambiental na preservação de serpentes. 2013. Trabalho de Conclusão de Curso (Bacharelado em Ciências Biológicas) - Instituto de Biociências, Universidade Estadual Paulista, Botucatu.

KOSZELA, I. C.; RAMOS, O. F. Experiências da comunidade caiçara: condições de pertencimento à comunidade rural de Guaratuba/PR. In: Secretaria da Educação Governo do Estado do Paraná. O professor e os desafios da escola pública paranaense. Curitiba: SEED, v. 2, p. 2-23, 2012.

LIMA, B. S. et al. Investigando o conhecimento etnoherpetológico dos cafeicultores sobre as serpentes do município de Inconfidentes, Mingas Gerais. Ethnoscientia, Botucatu, v. 3, p. 1-13, 2018.

LINS, J. et al. Construindo uma proposta metodológica de pesquisa participativa a partir do diálogo entre Educação do Campo e Etnobiologia. Revista Diálogos, Cuiabá, v. 12, p. 47-56, 2011.

MARQUES, J. G. W. "Do canto bonito ao berro do bode": percepção do comportamento de vocalização em aves entre camponeses alagoanos. Revista de Etologia, ed. especial, p. 71-85, 1998.

MARQUES, J. G. W. "Pássaro é bom para se pensar": simbolismo ascensional em uma Etnoecologia do Imaginário. Revista Incelências, v. 1, n. 1, 2-17, 2010.

MORAES, R.; GALIAZZI, M. do C. Análise Textual Discursiva. 3. ed. Ijuí: Unijui, 2016. 264p.

MORAES, R. Uma tempestade de luz: a compreensão possibilitada pela análise textual discursiva. Ciência \& Educação, v. 9, n. 2, p. 191-211, 2003. 
MOURA, M. R., et al. O relacionamento entre pessoas e serpentes no leste de Minas Gerais, sudeste do Brasil. Biota Neotropica, v. 10, n. 4, p. 133-141, 2010.

MUYLAERT, C. J. et al. Entrevistas narrativas: um importante recurso em pesquisa qualitativa. Revista da Escola de Enfermagem da USP, São Paulo, v. 48, esp. 2, p. 184-189, 2014.

OLIVEIRA, K. A.; CORONA, H. M. P. A percepção ambiental como ferramenta de propostas educativas e de políticas ambientais. Revista Científica ANAP Brasil, n. 1, p. 53-72, 2008.

PARANÁ. COPEL. Estudo de Impacto Ambiental UHE Apertados. Curitiba: Copel, 2012.

PARANÁ. Coordenadoria Estadual da Defesa Civil - Mapa. Curitiba: Defesa Civil, 2020.

PRADO, H. M.; MURRIETA, R. S. S. A etnoecologia em perspectiva: origens, interfaces e correntes atuais de um campo em ascensão. Ambiente \& Sociedade, São Paulo, v. 18, n. 4, p. 139-160, 2015.

ROSA, M.; OREY, D. C. Aproximando diferentes campos de conhecimento em educação: a Etnomatemática, a Etnobiologia e a Etnoecologia. Vydia, Santa Maria, v. 34, n. 1, p. 1-14, 2014.

SANTOS, C. A. B. et al. Do mau agouro à arte: a coruja no imaginário popular. Revista de Educação do IDEAU, Bagé, v. 10, n. 22, p. 1-13, 2015

SANTOS-FITA, D; COSTA NETO, E. M. As interações entre os seres humanos e os animais: a contribuição da etnozoologia. Biotemas, Florianópolis, v. 20, n. 4, p. 99-110, 2007.

SILVA, T. R. A etnobiologia utilizada como ferramenta para a prática da educação ambiental. Revista Sergipana de Educação Ambiental, Aracajú, v. 1, n. 3, p. 142-152, 2016.

SOUZA PERRELLI, M. A. et al. Saberes tradicionais sobre as serpentes e implicações para educação ambiental intercultural. Série Estudos. Periódico do Programa de Pós-Graduação em Educação da UCDB, Campo Grande, n. 30, p. 363-381, 2013.

TRÉZ, T. A. Feyerabend, interculturalismo e etnobiologia: algumas possíveis articulações no ensino de Biologia. Biotemas, Florianópolis, v. 24, n. 3, p. 128-140, 2011.

VINUTO, J. A amostragem em bola de neve na pesquisa qualitativa: um debate em aberto. Temáticas, Campinas, n. 44, ano 22, p. 201-2218, 2016.

ZACARIAS, E. F. J.; HIGUCHI, M. I. G. Relação pessoa-ambiente: caminhos para uma vida sustentável.

Interações, Campo Grande, v. 18, n. 9, p. 121-129, 2017. 